\title{
Management of a cutaneous squamous cell carcinoma in an American flamingo (Phoenicopterus ruber).
}

\begin{abstract}
A 32-year-old female American flamingo (Phoenicopterus ruber) was presented with a squamous cell carcinoma of the middle digit of the right foot. No clinical, hematologic, or radiologic evidence of metastasis was present. Salvage amputation of the digit resulted in complete cure, whereas previous electrosurgery and radiation therapy were unsuccessful. Three years later, another squamous cell carcinoma was diagnosed in the middle digit of the left foot. The digit was also amputated. Seven months after the second amputation, the bird did not have any recurrence or signs of metastasis.
\end{abstract}

Keyword: squamous cell carcinoma, surgery, radiation therapy, avian, American flamingo, Phoenicopterus ruber 